\title{
Achitecture of Porous Hydroxyapatite Scaffolds Using Polymer Foam Process*
}

\author{
Zin-Kook KIM**, Jeong-Jung OAK***, Hisamichi KIMURA***, \\ Takashi GOTO***, Akihisa INOUE*** and Seog-Young YOON** \\ **School of Materials Science and Engineering, Pusan National University, Busan, 609-735, South Korea \\ E-mail:syy3@pusan.ac.kr \\ *** Institute for Materials Research, Tohoku University, Aoba-ku, Katahira 2-1-1, Sendai, 980-8577, Japan
}

\begin{abstract}
Newly approach using the formation process of polymer foam is introduced in this study to prepare porous hydroxyapatite (HAp) scaffolds for bone tissue engineering applications, which could provide a better control over the microstructures of scaffolds and enhance their mechanical properties. The scaffolds prepared have an open, relatively uniform and interconnected porous structure with a pore size ranging 50 to $300 \mu \mathrm{m}$. A compressive strength of $5 \mathrm{MPa}$ for the scaffolds with HAp content $80 \mathrm{wt} \%$ and higher porosity of $77 \%$ was achieved. The pore morphology and size of the scaffolds were characterized using a scanning electron microscopy. X-ray diifraction was used to determine the crystal structure. Scaffolds with desired porosity, pore size, and geometry could be prepared by using the formation process of polymer foam with controlling process parameters.
\end{abstract}

Key words: Porous, Hydroxyapatite, Scaffold, Polymer, Foaming

\section{Introduction}

Recently, tissue engineering has emerged as one such promising approach for bone repair and reconstruction ${ }^{(1)}$. Tissue engineering involves the expansion of cells from a small biopsy, followed by the culturing of the cells in temporary 3D scaffolds to form the new organ or tissue ${ }^{(2)(3)(4)}$. With this approach, the 3D scaffold serves an important role in the manipulation of the functions of osteoblasts and a central role in the guidance of new bone formation into desired shapes. Therefore, the scaffold materials must be biocompatible, osteoconductive, and osteointegrative, and have enough mechanical strength to provide structural support. Hydroxyapatite $\left(\mathrm{Ca}_{3}\left(\mathrm{PO}_{4}\right)_{6}(\mathrm{OH})_{2}, \mathrm{HAp}\right)$ has been widely used in medicine and dentistry because it is biocompatible, osteoconductive, and has excellent chemical and biological affinity with bony tissue ${ }^{(5)}$. As a result, HAp is accepted as a bioactive scaffold material for guided bone regeneration. In addition to the requirements for chemical composition of the scaffold material, a 3D interconnected porous structure is necessary to allow cell attachment, proliferation, and differentiation, and to provide pathways for biofluids. However, it is well known that the mechanical strength of a material decreases as its porosity increases. Thus, the improvement on mechanical resistance of porous scaffolds for bone tissue engineering should be needed without decreasing their porosity. A lot of methods have been developed to fabricate porous HAp scaffolds including incorporation of volatile ${ }^{(6)}$ or combustible burnout of organic particles in the HAp powder ${ }^{(7)}$, gel casting of foams ${ }^{(8)}$, and replication of a porous substrate ${ }^{(9)}$. However, none of these methods can satisfy all of requirements such as high porosity, perfect interconnection, and high mechanical properties. For example, the method of incorporation of organic particles with ceramic powder results in a porous structure of closed and poorly interconnected. Gel 
casting of foams is a common technique for fabricating ceramic scaffolds with high mechanical strength, but it usually results in a structure of poorly interconnected pores, and non-uniform pore size distribution. In recent, Ramay and Zhang ${ }^{(10)}$ reported a new technique that integrates the gel-casting technique with polymer sponge method to prepare HAp porous scaffolds with improved mechanical strength and controllable porous structure. However, the reticulated porous ceramics produced by this method often have poor mechanical properties because of the defects generated during the pyrolysis of the polymer foam. Araki and Halloran ${ }^{(11)}$ tried to produce the porous structured ceramics with the freeze casting method. In this method, three-dimensionally interconnected pore channels would be readily produced by removing the frozen vehicle network via sublimation. To date, water and camphene have been adopted as the vehicle materials. However, they did not obtain the sufficient porosity compared to compressive strength. In this study, we opted to use the formation process of polymer foam with generating $\mathrm{CO}_{2}$ gas in order to prepare porous HAp scaffolds with improved mechanical strength and controllable porous structure. The pore structure (such as porosity, pore size, and interconnection) and compressive strengths for the scaffolds prepared under processing conditions were investigated, in order to evaluate the possibility of using these materials as bone scaffolds.

\section{Experimental}

A commercial hydroxyapatite (HAp) powder $\left(\mathrm{Ca}_{10}\left(\mathrm{PO}_{4}\right)_{6}(\mathrm{OH})_{2}\right.$; DC Chemical Co., Korea) was selected as the bioactive material. Commercial polyol (SK Evertec Co., Korea) and isocyanate (SK Evertec Co., Korea) were used as the constituents for polymer foam process. HAp/ polyol slurries with different HAp contents $(60,70$, and $80 \mathrm{wt} \%$ of polyol) were deagglomerated by ball milling for $24 \mathrm{~h}$ and subsequently removed bubbles under vacuum until no further release of air bubbles from mixture, and then isocyanate $(27.8 \mathrm{wt} \%$ of polyol) was added. The HAp/polyol/isocyanate mixture was immediately poured into molds with a rectangular parallelepiped container $(10 \times 10 \times 10 \mathrm{~mm})$ onto brass plate. Typically, less than 30 min was required for the complete solidification of the cast body. Before demolding, the green body was placed on brass plate in a room temperature to enhance their green strength. The green body was removed from mold, and then dried in air for $24 \mathrm{~h}$. After the drying, the green body was heated at a rate of $3^{\circ} \mathrm{C} / \mathrm{min}$ to $600^{\circ} \mathrm{C}$. The green body was heated at this temperature for $1 \mathrm{~h}$ to burnout the polymer foams, and then sintered at a rate of $5^{\circ} \mathrm{C} / \mathrm{min}$ to $1200^{\circ} \mathrm{C}$ and $1350^{\circ} \mathrm{C}$ for a dwell time of $2 \mathrm{~h}$. The process of polymer burnout was incorporated with sintering to avoid handling of the green body.

Thermogravimetric analysis (TGA) is used to measure the thermal stability and composition of a material. It measures weight changes in a material as a function of temperature under a controlled atmosphere. TGA [TG/DTA, DTG-60H, Shimazu, Japan] was used to study the pyrolysis process of polymer foam and determine the temperature of burning the polymer foam off. X-ray diffraction (XRD) analysis was used to characterize the crystallinity, chemical composition, and structure of the material. The crystallinity of the obtained scaffolds was characterized by means of XRD [D/max-IIA, Rigaku], using $\mathrm{Ni}$-filtered $\mathrm{CuK} \alpha$ radiation at $30 \mathrm{kV}, 40 \mathrm{~mA}$. Scanning electron microscopy (SEM) [JSM-840A, JEPL, Japan] technique was used to observe the microstructure, pore configuration, and pore size for the scaffolds. The porosity and density of the obtained scaffolds were calculated using a liquid displacement method. The inside pore structures of the scaffolds were directly observed from the fractured surface. For the compressive strength test, the scaffolds $(7 \times 7 \times 7 \mathrm{~mm})$ were loaded at a crosshead speed of $0.4 \mathrm{~mm} / \mathrm{min}$ using a screw driven load frame (Instron 4505, Instron Corp., USA). The stress and strain responses of the scaffolds were monitored during the compressive strength tests. More than five samples were tested to obtain the average value along with its standard deviation. 


\section{Results and Discussion}

Porous HAp scaffolds were prepared using polymer foam process containing HAp, polyol, and isocyanate. In general, pyrolysis of a polymer is critical in sintering ceramics using the polymer materials ${ }^{(7)}$. Sufficient time should be given for the polymer burnout before the sintering of ceramics starts to avoid cracks in the microstructure. In this study, TGA was carried out to determine the firing temperature at which the complete burnout of the polymer foam occurred. Fig. 1 shows the weight change of the polymer foam with temperature. It is seen that the polymer foam could be completely burned out at $600^{\circ} \mathrm{C}$. Therefore, to allow sufficient time for the complete burnout of the polymer in HAp scaffolds before the sintering process started, the heating rate was set to $3^{\circ} \mathrm{C} / \mathrm{min}$ up to $600^{\circ} \mathrm{C}$ with a dwell time of $1 \mathrm{~h}$.

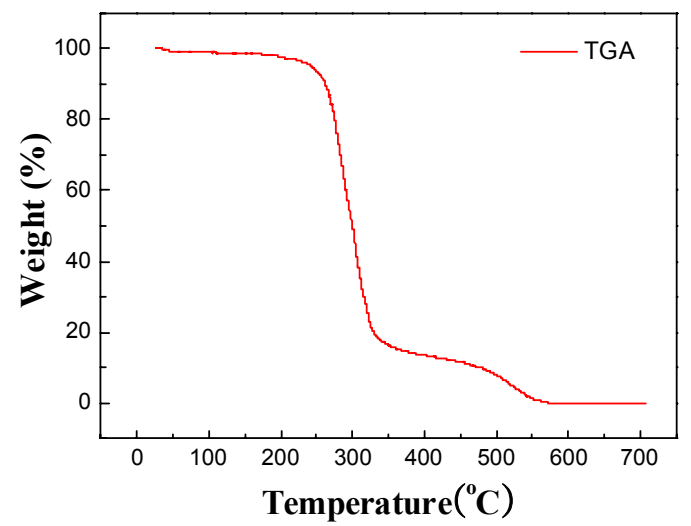

Fig.1. Weight loss as a function of temperature

for pyrolysis of polymer foam.

The decomposition of HAp powder at temperature above $1150^{\circ} \mathrm{C}$ was reported ${ }^{(12)}$. Thus preserving the phase composition and crystalline structure of HAp during sintering becomes critical for its biological applications. Fig.2 shows the XRD patterns of the HAp powder as-received and the material after being sintered at $1200^{\circ} \mathrm{C}$ and $1350^{\circ} \mathrm{C}$. The XRD peaks of all three diffraction patterns agree with those of standard $\mathrm{HAp}$ in the powder diffraction file (JCPDS NO.

9-432). No discernible difference among the three patterns was observed, and no additional phase was identified. This is consistent with the other previous report, which the composition of HAp was not changed during the sintering process regardless of HAp contents ${ }^{(10)}$. This high thermal stability of HAp materials shown in this study allows for attaining a fully densified structure at high sintering temperatures.

Figure 3 represents the SEM micrographs of the green body (before sintering) and sintered body. The sintered body preserved their highly porous structures with interconnected and macroporous and microporous with dimensions of $50 \sim 300 \mu \mathrm{m}$. Moreover, the macroporous structure was not changed appreciably throughout the entire sample with sintering process at low magnification (Fig.3 (a) and (b)).

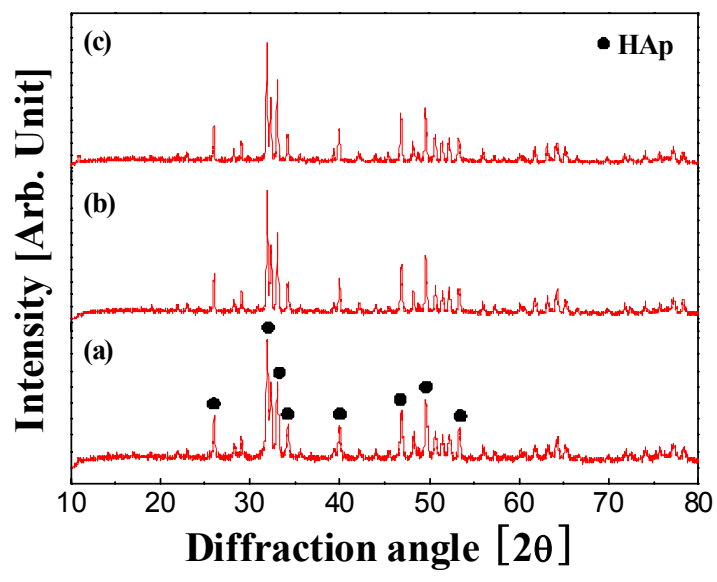

Fig. 2. XRD patterns for (a) HAp powder; (b) sintered at $1200^{\circ} \mathrm{C}$; and (c) sintered at $1350^{\circ} \mathrm{C}$ 


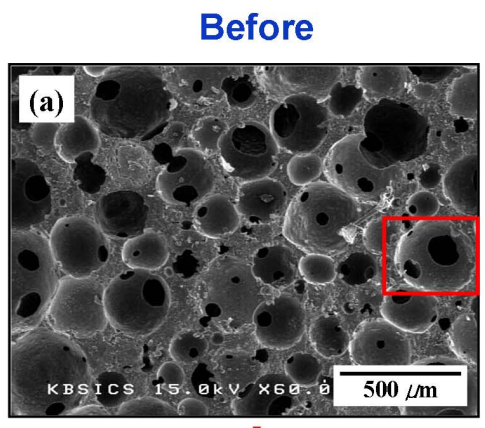

$\downarrow$
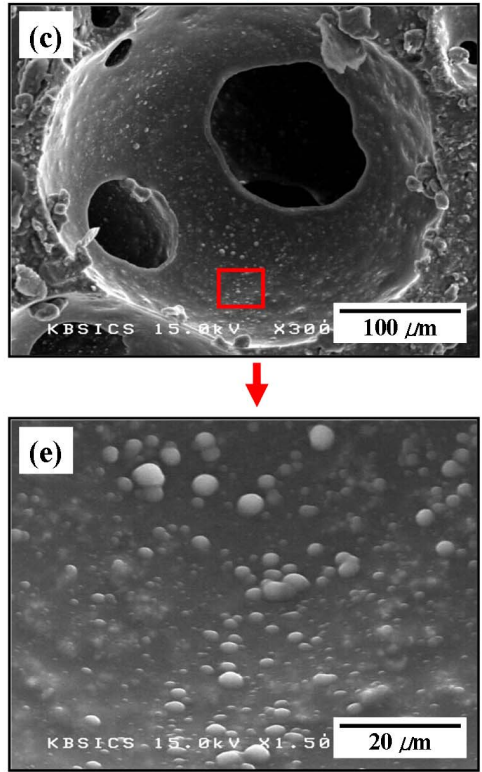

Fig.3. SEM micrographs of the scaffolds before and after sintering process with different magnification. The scaffolds were prepared $70 \mathrm{wt} \%$ HAp and sintered at $1200^{\circ} \mathrm{C}$.

This behavior would be explained with the formation process of polymer foam block as shown in Fig. 4. As can be seen in Fig. 4, the initial pore in green body could be introduced by the $\mathrm{CO}_{2}$ gas evaporation during the reaction between HAp/polyol and isocyanate. During burnout of the polymer components in HAp scaffolds, the initial pores were gradually grown and touched each other, and then finally become to be large and wide as shown in Fig. 3(a) and (b).

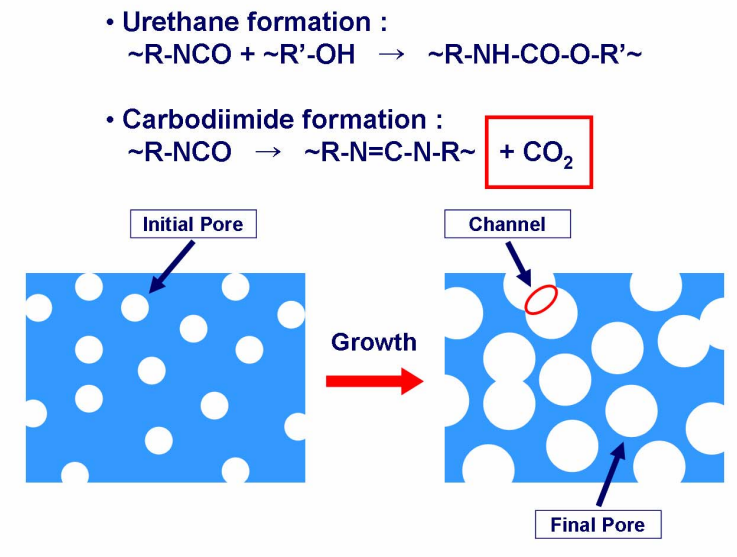

Fig. 4. The proposal formation process of polymer foam and pore interconnection
Before sintering, the pore channel was not much observed, whereas the pore channels was occurred in the sample after sintered as shown in Fig.3 (c) and (d). This phenomenon would be explained that the pore channels would be generated by the connecting between grown pores during burnout process for removing polymer components from HAp scaffolds matrix as 
shown in Fig. 4. At higher magnification, the morphologies of pore channels and walls are more clearly visible, as shown in Fig.3 (e)-(f). The pore channels had microporous structure with dimensions of few tenth microns, whereas pore walls was relatively well densified, indicating that the HAp powder was fully sintered at $1200^{\circ} \mathrm{C}$. The submicro-sized pore in the pore channels would be generated by the evaporation of residual polymer components during the sintering process, which could reduce mechanical strength of the structure. The scaffolds are required to reproduce the bone characteristics not only in terms of composition but also in terms of pore morphology. Porous materials allow development of bone and soft tissues within large pores and also blood supply for further bone mineralization. Fig. 5 shows the cross-sectional surface of scaffolds prepared using solid content of $70 \%$ HAp and sintered at $1200^{\circ} \mathrm{C}$. Inside surface of HAp scaffolds had the interconnected and macro-porous structure with pore sizes ranging from 50-300 $\mu \mathrm{m}$. The results of the morphological investigation indicate that the method used here allows the preparation of HAp scaffolds with a 3D interpenetrating network of struts and pores. Hulbert et al. ${ }^{(13)}$ suggested that the optimum pore size for osteoconduction is $150 \mu \mathrm{m}$. On the other hand, Flatley et al. ${ }^{(14)}$ reported that a pore size of $500 \mu \mathrm{m}$ is compatible for osteoconduction. An interconnected open pore structure is also essential for a material to serve as a temporary scaffold for bone tissues because it allows biomolecules and degraded substances to freely flow into and out the scaffold ${ }^{(15)}$. On the basis of morphological observations, the scaffolds with the pore size and an interconnecting pore structure shown in Fig. 3 and 5 would be suitable applications as bone tissue engineering scaffolds.

Fig. 6 shows the porosity of scaffolds

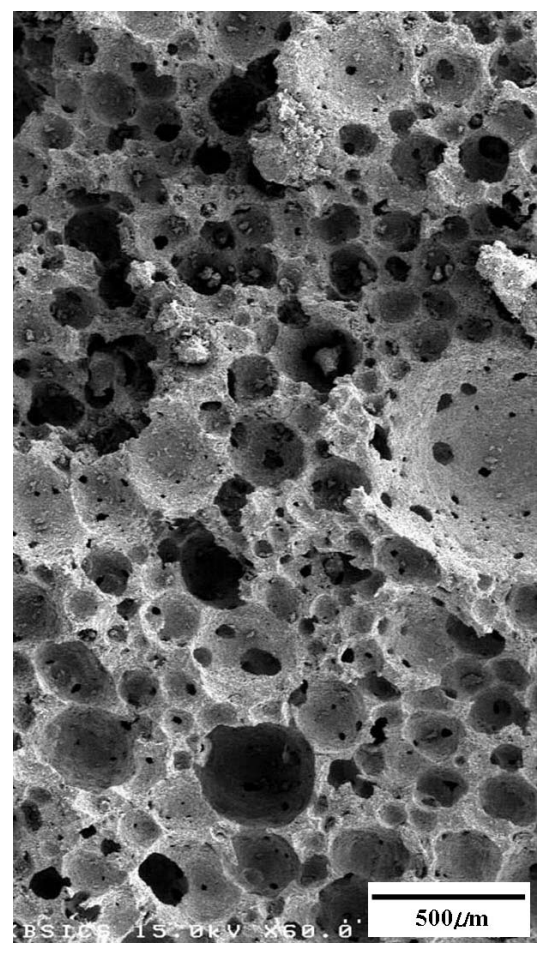

Fig. 5. SEM micrograph of the fracture surface of porous HAp scaffolds sintered at $1200^{\circ} \mathrm{C}$. prepared with different HAp contents. Porosity characterization is based on the presence of open pores which are related to properties such as permeability and surface area of the porous structure. High porosity usually means a high surface area /volume ratio, and thus favors cell adhesion to the scaffold and promotes bone tissue regeneration. As the HAp concentration increased, the porosity of scaffold slightly decreased as shown in Fig. 6. These phenomena would be attributed that the pores became interconnected with more dense and thicker pore walls with increasing of the HAp content in scaffold. It is worthwhile mentioning that the density of a scaffold decreases with the level of porosity at constant HAp content. Since a higher density usually leads to higher mechanical strength while a high porosity provides a favorable biological environment, a balance between porosity and density for a scaffold must be established for the specific application. Generally, the strength of porous scaffold is strongly affected not only by the strength of the pore wall, but also by the surface flaws on the pore wall. In order to evaluate the mechanical properties of scaffolds prepared with different HAp contents, compressive strength tests were conducted. The stress increased linearly with the elastic response for all the prepared scaffolds and then dropped rapidly due to fast fracture, in the same manner that brittle porous ceramic 
materials fail during compression. The compressive strength was slightly increased from 1 to $5 \mathrm{MPa}$ by decreasing of the porosity from 79 to $77 \%$, as shown in Fig.6. These values are comparable than those reported in the literature ${ }^{(16)(17)}$. HAp scaffolds prepared by the polymer sponge method, in general, had a typical compressive strength of around $2 \mathrm{MPa}^{(10)}$. Clearly, the new approach introduced in this study has increased the mechanical properties over the general polymer sponge method without decreasing the porosity. This behavior would be attributed to the full densification of the HAp scaffolds wall and well-interconnected pore structure.

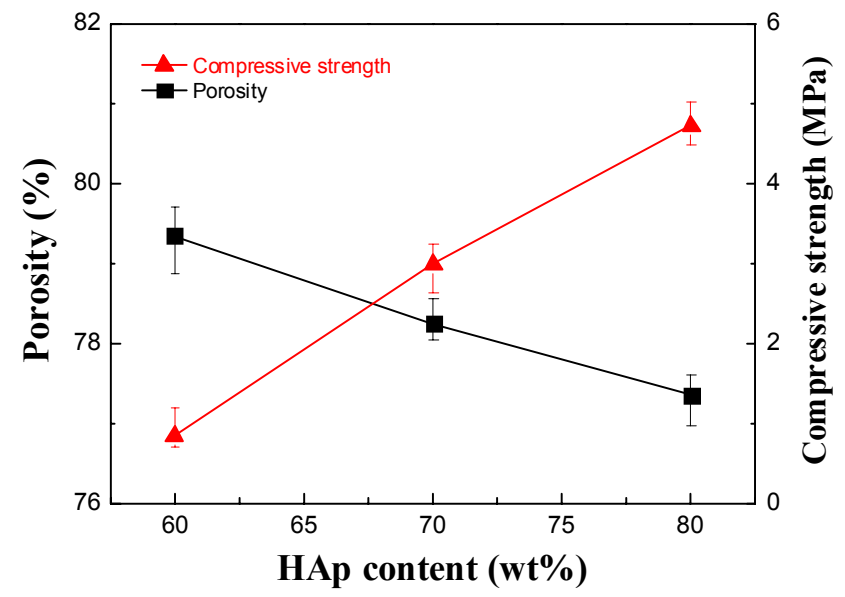

Fig.6. Porosity and compressive strength of the HAp scaffolds as a function

of the HAp content

\section{Conclusions}

Porous HAp scaffolds were successfully prepared by using the formation process of polymer foam with polyol and isocyanate components. The obtained scaffolds with a pore size ranging 50 to $300 \mu \mathrm{m}$ were prepared that have an interconnected macroporous microporous structure. The macroporous structure of the produced HAp scaffolds would be generated not only by the $\mathrm{CO}_{2}$ gas evaporation during the reaction between HAp/polyol and isocyanate and but also by burnout of the polymer components in HAp scaffolds. On the other hand, the microporous structure in pore wall and channels would be generated by the evaporation of residual polymer components during the sintering process. A compressive strength of $5 \mathrm{MPa}$ for the scaffolds with HAp content $80 \mathrm{wt} \%$ and higher porosity of $77 \%$ was achieved. With this method, the pore size and shape of scaffold could be controllable because the scaffolds are formed by in situ polymerization. On the basis of morphological observations, the obtained HAp scaffolds having the pore size and an interconnecting pore structure would be suitable applications as bone tissue engineering scaffolds. As the HAp content increased, the porosity and density of scaffold decreased and increased, respectively. These phenomena would be attributed that the pores became interconnected with more dense and thicker pore walls with increasing of the HAp content. As a result, it suggested that the density, porosity, and compressive strength of the porous HAp scaffold were significantly affected by the content of the HAp. 


\section{Acknowledgments}

A part this work was carried out under the Visiting Professor Program of Advanced Research Center of Metallic Glasses, Institute for Materials Research, Tohoku University.

\section{References}

(1) Service, RF., Tissue engineers build new bone, Science, Vol. 289 (2000), pp. 1498-1500.

(2) Hutmacher, DW., Scaffolds in tissue engineering bone and cartilage, Biomaterials, Vol.21 (2000), pp.2529-2543.

(3) Devin, JE., Attawia, MA., Laurencin, CT., Three-dimensional degradable porous polymer-ceramic matrices for use in bone repair, Journal of Biomaterial Science Polymer Edition, Vol.7(8) (1996), pp.661-669.

(4) Laurencin, CT., Lu, HH., Polymer-ceramic composites for bone tissue engineering, In; Davies, JE, editor, Bone engineering, (2000), pp.462-472.

(5) Hench, LL., Bioceramics: from concept to clinic, Journal of the American Ceramic Society, Vol. 74 (1991), pp.1487-1510.

(6) Livingston, T., Ducheyne, J., Garino, In vivo evaluation of a bioactive scaffold for bone tissue engineering, Journal of Biomedical Materials Research, Vol.62 (2002), pp.1-13

(7) Li, S.H., De Wijn, J.R., Layrolle, P., de Groot, K., Synthesis of macroporous hydroxyapatite scaffolds for bone tissue engineering, Journal of Biomedical Materials Research, Vol. 61 (2002), pp.109-120.

(8) Sepulveda, P., Binner, J.G.P., Processing of cellular ceramics by foaming and in situ polymerization of organic monomers, Journal of the European Ceramic Society, Vol. 19 (1999), pp.2059-2066.

(9) Callcut, S., Knowles, J.C., Correlation between structure and compressive strength in a reticulated glass-reinforced hydroxyapatite foam, Journal of Materials Science:Materials in Medicine, Vol.13(2002), pp.485-489.

(10) Ramay, H.R., Zhang, M., Preparation of porous hydroxyapatite scaffolds by combination of the gel-casting and polymer sponge methods, Biomaterials, Vol.24 (2003), pp.3293-3302.

(11) Araki, K., Halloran, J.W., Porous ceramic bodies with interconnected pore channels by a novel freeze casting technique, Journal of the American Ceramic Society, Vol. 88 (2005), pp. 1108-1114.

(12) Tampieri, A., Celotti, G., Szontage, F., Landi, E., Sintering and characterization of HA and TCP bioceramics with control of their strength and phase purity, Journal of Materials Science: Materials in Medicine, Vol. 8 (1997), pp.29-37.

(13) Hulbert, SF., Morrison, JS., Klawitter, JJ., Tissue reaction to three ceramics of porous and non porous structures, Journal of Biomedical Materials Research, Vol.6 (1972), pp.347-374.

(14) Flatley, TJ., Lynch, KL., Benson, M., Tissue response to implants of calcium phosphate ceramic in the rabbit spine, Clinical Orthopaedic, Vol.179 (1983), pp.246-252.

(15) Sepulveda, P., Ortega, FS., Innocentini, MDM., Pandolfelli, VC., Properties of highly porous hydroxyapatite obtained by the gelcasting of foams, Journal of The American Ceramic Society, Vol.83 (2000), PP.3021-3024.

(16) Hing, KA., Best, BM., Bonfield, W., Characterization of porous hydroxyapatite, Journal of Materials Science, Vol.10 (1999), pp.135-145.

(17) Lee, EJ., Koh, YH., Yoon, BH., Kim, HE., Kim, HW., Highly porous hydroxyapatite bioceramics with interconnected pore channels using camphene-based freeze casting, Material Letters, Vol.61 (2007), pp.2270-2273. 